\title{
Web 2.0 for Reference Services Staff Training and Communication
}

Jane Currie

jcurrie@luc.edu

Follow this and additional works at: https://ecommons.luc.edu/lib_facpubs

Part of the Library and Information Science Commons

\section{Recommended Citation}

"Web 2.0 for Reference Services Staff Training and Communication" Reference Services Review, 38.1 (2010): 152-157.

This Article is brought to you for free and open access by the Faculty Publications and Other Works by Department at Loyola eCommons. It has been accepted for inclusion in University Libraries: Faculty Publications and Other Works by an authorized administrator of Loyola eCommons. For more information, please contact ecommons@luc.edu.

\section{cc) (i) $\ominus$}

This work is licensed under a Creative Commons Attribution-Noncommercial-No Derivative Works 3.0 License. Copyright @ 2010 Jane Currie 
Coordinated communication and training for the members of a reference services department are essential to its success internally and its provision of quality service. This essay focuses on applications of Web 2.0 that improve training and communication within the reference services department. Managers of reference services whose staff includes student employees, non-student staff, professional librarians, or a combination thereof may adopt its suggestions.

Reference services are often provided, in part, by non-professional and part-time staff including, in academic settings, student employees. Today's student employees are adept with many Web 2.0 technologies [1]. Other staff members have likely become familiar with Web 2.0 through their library's application of it for outreach [2] and, perhaps, through personal use. By applying Web 2.0 communication and information tools to the provision of reference services, employees are empowered in their role as providers of effective assistance to researchers. These technologies also allow supervisors to apply a participatory management approach, using the individual experiences of all staff members, professional and non-professional, to improve the knowledge and skills of each individual and the group as a whole.

Interactivity distinguishes Web 2.0 technologies from other electronic tools. Users not only access content but make it their own by contributing, editing, or generating it. This essay features some of the best known and most heavily used examples Web 2.0: blogs, calendars, wikis, RSS, image collections, podcasts or vodcasts, social bookmarks, text messages, instant messages, and social networks [3]. Each has the potential to contribute new means for training and communicating in the reference services setting.

\section{Blogs}

Ubiquity and simplicity make a blog an ideal initial application of Web 2.0 to reference department operations [4]. A blog with frequent posts, comments, and responses to those comments exhibits the "read/write Web" that characterizes all of Web 2.0. For example, the supervisor who titles a blog post "Scheduled database maintenance tomorrow" can share with the entire staff as each member begins a shift which database will be inaccessible, when, and for how long. The post may also describe alternative databases to recommend to users affected by the outage. When the database becomes accessible again, any staff member can add a comment to that effect. Assigning a category to each post simplifies referencing one again. Those archived posts and comments may provide a supervisor with ideas for service or training improvements when similar circumstances arise.

Supervisors need not be the only initiators of blog posts. All members of the staff can contribute. In one scenario, a student employee covering a solo shift may hear the same question from several students, prompting the student employee to ask for details about the assignment. Having discovered the class, the level of the students enrolled, and the nature of their assignment, this information can be posted to the blog for reference by other employees on later shifts. Those members of the staff may add comments as they ascertain the best resources for the assignment. An instruction librarian may comment with especially helpful insight into the assignment's research objectives. Such posts and comments help staff members with the immediate need and serve as training resources for similar situations in the future. 
Reserving this communication for the blog rather than using e-mail exchanges has several benefits. It prevents student employees from having work-related e-mail messages among all of the academic and personal e-mail they receive each day. The blog allows student employees to concern themselves with work-related matters only when they are at work and non-student staff to focus on their reference-related responsibilities at the appropriate times without concerning themselves with it when they want to be focused on other areas. Secondly, requiring that each staff member maintain an accurate department e-mail distribution list is an onerous task compared with the ease of administering a blog's users. Third, as mentioned already, an archive of blog posts has value for training and assessing best practices.

Thanks to freely available blogging tools such as WordPress and Blogger, a reference department may start a blog without encumbering any direct expense and with only a few hours' time dedicated to establishing the list of users, a set of meaningful categories, and basic administrative features. Once the blog is ready members of the department should be encouraged to review all changes to it that have appeared since their last shift (both new posts and new comments to ones already read). Since an effective blog is an active one, repeated reminders to read and contribute may be necessary initially. As staff members discover the value of the blog for facilitating communication posting and commenting will become habits.

\section{Online Calendars}

An advantage for choosing Blogger, a Google tool, for the department blog is the option to use the same account to create a Google Calendar as an interactive, real time department scheduling system that is consistent with the principles of Web 2.0. Each reference shift can be entered into the online calendar. When a staff member recognizes a conflict with an assigned shift, the shift can be marked using a predefined color to indicate that a substitute is needed. After another staff member accepts the shift the color can be changed again, along with the name of the staff member who will be working, to indicate that the substitution is in place. By hosting the calendar online, it is accessible to all employees from any computer at any time. The interactivity of the calendar promotes shared responsibility for maintaining an accurate, up-to-date schedule.

\section{Wikis}

Some complex resources that a reference department supports change often and may be used infrequently by members of the staff. These are ideal candidates for a wiki, another Web 2.0 tool that can facilitate training and communication. Initially, one or a team of staff members can establish the wiki using a freely-available tool such as PBworks. Once it is in place, all members of the staff can add updates, best practices, and ways in which the featured resource has been used successfully in reference interactions. The department supervisor or a designated staff member should routinely review the wiki to ensure that provided information is accurate and straightforward. A wiki promotes peer teaching and creates a repository of shared knowledge valuable to all members of the department at their time of need.

\section{RSS Feeds}


Whether using a blog, online calendar, wiki, or a combination of the three, another Web 2.0 technology that will assist staff members in staying current is establishing a RSS (Rich Site Summary or, alternatively, Real Simple Syndication) feed to accompany each tool. While some staff members may prefer to check the blog, calendar, and wiki for updates at the start of each shift, others may prefer to know about changes as they happen. This function may be especially valuable to a supervisor. RSS provides an alert to a new blog post, calendar revision, or wiki update within another technology; via a RSS feed reader that the staff member may access at a computer or with a mobile device, or through an e-mail alert.

\section{Online Photo Collections}

Online photo collections offer staff members a resource for learning library locations and referring users to them when answering directional questions. The tagging features that apply folksonomies [5] and are inherent in Web 2.0 tools such as Flickr, a host of online images, allow library staff and users to overcome the differences in terminology that sometimes create confusion or inconsistencies in the names used for physical locations. For example, a photo of the circulation desk can be loaded into a Flickr pool of library location images and tagged "circulation desk" and "checkout desk" as well as any other locally used terminology for it. The insights of student employees in tagging the photos collected in a Flickr pool are invaluable as they have both the perspective of the library employee and that of the typical user in their awareness of formal and informal terms for locations, collections, and services. They can help those who have worked in libraries for extended periods gain the perspective of users who are unfamiliar with the nomenclature of library science and the library facility.

\section{Podcasts and Vodcasts}

Podcasts, created and hosted at sites such as Ourmedia, or vodcasts, posted at YouTube or elsewhere, provide another means for training through Web 2.0. Podcasts and vodcasts may be created quickly, tested, and revised for improvement. Practicing the techniques for instruction via these technologies for internal training may help staff members gain confidence in their podcasting and vodcasting skills, expanding the group of employees who are able to create them for the library's users. A wealth of instructional information can be conveyed to employees via podcast or vodcast, from locating a title in the collection using a call number to techniques for searching a particular database.

\section{Social Bookmarks}

Reference librarians all have favorite reference websites they access using a bookmark or simply through a memorized URL. Non-student and student staff can benefit from a shared repository of bookmarks when lists of them are accessible in a Web 2.0-based social bookmarking tool such as Delicious. Here, too, folksonomies are used. Tags assigned to websites can reflect formal and informal terminology used to connect assignments and subject areas to especially valuable sources. In addition, stable URLs may be added to the department's Delicious list that link into the library's subscribed resources where frequently asked reference questions are answered.

\section{Microblogs and Text Messages}


Web 2.0 technologies offer reference departments tools to facilitate instant communication in the event of an emergency or an urgent matter. The first of these is micro-blogging and text messaging. Twitter, the best known micro-blogging service, allows members of the department to send and receive messages via Twitter itself or by using their own mobile device's Short Message Service. For example, a student employee due for a reference shift but delayed by a lecture, lab, or line across campus can send a text message to the reference department, notifying staff working the current shift as well as their supervisor. Last-minute adjustments can be made to the schedule before the shift begins rather than only after members of the department realize that their colleague is delayed or absent entirely.

\section{Instant Messages}

Instant messaging (IM) tools provide another means for internal, emergency communication. While the public desks at many libraries are using IM services such as Meebo to communicate with users, the possibilities for aiding interdepartmental communication between service points may not have been considered. Public desks are staffed nights and weekends, hours when other parts of the library are vacant of employees. Security-related concerns are heightened by the reduced staff presence and probable higher ratio of student to non-student staff. During these hours, it is especially important that employees at public desks can share with one another information regarding individuals in the building and observations of unusual behaviors. In sensitive situations such concerns may not be safely vocalized over the telephone but can be shared via computer using IM. Staff at one desk can alert others of an issue or ask that security be called.

\section{Social Networks}

Social networks, primary among them Facebook, may be the Web 2.0 technology that is most ubiquitous in the lives of student employees. As with most facets of Web 2.0, libraries have used Facebook for outreach, first with individual librarians creating their own Facebook profile and more recently, with the advent of the organizational Facebook profile, one for the library itself. The library's Facebook profile is commonly used to promote new materials, inform users of events and hours, and reach users and prospective users in this online social environment. Libraries hope that users will become their fans within Facebook, helping us reach their Facebook friends who may, themselves, become our fans. Staff members with Facebook profiles can be encouraged to become fans of the library, helping spread the library's Facebook profile to an ever-growing group of potentially interested

Facebook users. By encouraging members of the reference department, especially student employees, to become Facebook friends of one another, we can also encourage camaraderie. This is especially important in an environment where staffing changes are common and some employees may see one another infrequently.

Implementing Web 2.0 tools to coordinate communication and training creates a dynamic, interactive system for sharing procedures, ideas, and new developments within a reference services department. Whether in the form of a blog, calendar, wiki, online photo collection, podcast or vodcast, shared bookmark collection, text message service, social network, or a combination thereof, a 
reference department may be managed more efficiently through the application of Web 2.0 technologies.

Featured Web 2.0 Tools

\begin{tabular}{|l|l|}
\hline $\begin{array}{l}\text { WordPress } \\
\text { Blogger }\end{array}$ & $\begin{array}{l}\text { http://wordpress.org } \\
\text { http://www.google.com/blogger }\end{array}$ \\
\hline Google Calendar & http://www.google.com/calendar \\
\hline PBworks & http://pbworks.com \\
\hline Google Reader & http://www.google.com/reader \\
\hline Flickr & http://www.flickr.com \\
\hline Ourmedia & http://www.ourmedia.org \\
\hline YouTube & http://www.youtube.com \\
\hline Delicious & http://www.delicious.com \\
\hline Twitter & http://twitter.com \\
\hline Meebo & http://www.meebo.com \\
\hline Facebook & http://www.facebook.com \\
\hline
\end{tabular}

[1] A 2007 Pew Internet and American Life Project report titled "Teens and Social Media" provided detailed insight into how teens use Web 2.0 tools in daily life. The report, authored by Amanda Lenhart, Aaron Smith, and Alexandra Macgill, may be viewed at http://www.pewinternet.org/Reports/2007/Teens-and-Social-Media.aspx.

[2] An introduction to applications of Web 2.0 tools for library outreach is Michael Stephen's "Exploring Web 2.0 and Libraries" published in Library Technology Reports, Vol. 42 No. 4 (2006) on pages 8-14. While Web 2.0 tools are popular in today's libraries, their use has been outwardly focused as means for reaching new users, reinforcing relationships with existing ones, promoting services, increasing awareness of resources, and disseminating noteworthy information rather than on internal use as communication and training tools; the focus of this essay. 
[3] A graphical introduction to Web 2.0 is incorporated into Jeff Howe's "Your Web Your Way" in the 25 December 2006 issue of Time, Vol. 168 No. 26, on pages 60-61.

[4] Jenna Wortham documents the growth of blogs in "After 10 Years of Blogs, the Future's Brighter than Ever" published in Wired on 17 December 2007 and accessible at http://www.wired.com/entertainment/theweb/news/2007/12/blog_anniversary.

[5] A Dictionary of the Internet (Oxford, 2009) defines folksonomy as, "the tagging of Internet content with some extra information that provides a description of the content.... The term is formed by combining the words folk (the users who carry out the tagging) and taxonomy (a form of structural organization)." 